\title{
Influence of Solution Treatment on Microstructure and Stress Rupture Properties of K439 Nickel-Base Superalloy
}

\author{
Jin $\mathrm{Xu}^{1,2}$, Mingjun Zhang ${ }^{1, *}$, Xin Tang ${ }^{1}$, Guangyu Yang ${ }^{2, *}$, Jingyang Chen ${ }^{1}$, Qing $\mathrm{Li}^{1}$, and \\ Chengbo $\mathrm{Xiao}^{1}$
}

${ }^{1}$ Science and Technology on Advanced High Temperature Structure Materials Laboratory, Beijing Institute of Aeronautical Materials, Beijing 100095, China; ${ }^{2}$ State Key Laboratory of Solidification Processing, Northwestern Polytechnical University, Xi'an 710072, China

Received: July 23, 2017 / Accepted: June 6, 2018

\begin{abstract}
Isochronal solution treatment in the $1,080-1,190{ }^{\circ} \mathrm{C}$ range for $4 \mathrm{~h}$ followed by air cooling has been performed to investigate the effects of solution temperature on the microstructure and stress rupture properties of a K439 Ni-base superalloy. The detailed as-cast and solution-treated microstructures were analyzed through optical microscopy, scanning electron microscopy and differential scanning calorimetry. The experimental results showed that the as-cast alloy exhibited a typical dendritic structure with five type microstructures of $\gamma, \gamma^{\prime}, \gamma / \gamma^{\prime}, \eta$ and MC. After solution heat treatment at $1,080^{\circ} \mathrm{C}$, although all of the $\gamma^{\prime}$ particles in the dendritic cores dissolved, there were some precipitates in the interdendritic regions beside the $\eta$ phase. When the solution temperature was raised to $1,150^{\circ} \mathrm{C}$, both of the $\gamma^{\prime}$ and $\eta$ solutioned and a uniform microstructure was observed. Furthermore, when the solution temperature was raised to $1,210{ }^{\circ} \mathrm{C}$, a small amount of incipient melting occurred in the alloy. The stress rupture lifetime of the K439 alloy at 760 ${ }^{\circ} \mathrm{C} / 530 \mathrm{MPa}$ increased with the solution temperature, which reached to the maximum value at the solution temperature of $1,150{ }^{\circ} \mathrm{C}$. The optimum solution treatment was considered to be $1,150{ }^{\circ} \mathrm{C} / 4 \mathrm{~h}$ followed by air cooling.
\end{abstract}

Keywords: K439 Ni-base superalloy; Solution treatment; Microstructure; Stress rupture property.

\footnotetext{
Corresponding authors: ygy@nwpu.edu.cn (Guangyu Yang); zmj621@126.com (Mingjun Zhang)
}

\section{Introduction}

Ascribing to its excellent mechanical properties, weldability and corrosion resistance, K4169 alloy, a Ni-Fe-based alloy, has been mainly used in the manufacture of large structural components of aircraft engines, such as turbine casings and diffusers (Whitmore et al., 2014; Demers et al., 2015). However, the coarsening of the $\gamma^{\prime}$ precipitates above $650{ }^{\circ} \mathrm{C}$ always causes significant reductions in strength and ductility of K4169 alloy, which limits its applications only in the range within $650{ }^{\circ} \mathrm{C}$ (Cone al., 2001; Dong et al., 1993; Dong et al., 1995). Increasing thrust and performance demands of advanced aircraft engines require materials capable of operating at higher temperatures. For example, the current generation of very high thrust commercial engines requires diffuser case materials with 56$111{ }^{\circ} \mathrm{C}$ higher in operating capability over the alloy (cast + HIP Inconel 718) used for lower thrust models. Therefore, the K439 Ni-based superalloy (Ni-Co-based alloy) with the service temperature up to $800^{\circ} \mathrm{C}$ was investigated by researchers at Beijing Institute of Aeronautical Materials, China, which could be used in casting large-size turbine casings.

The typical microstructure of the as-cast K439 alloy, consisting of massive coarser $\gamma^{\prime}$ precipitation and a small amount of $\gamma / \gamma^{\prime}$ eutectic and $\eta$ phase, leads to low mechanical properties (Wang et al., 2015; Long et al., 2009; Sajjadi et al., 2002). In order to augment the mechanical properties, proper solution treatment was carried out to improve the microstructure of K439 alloy. He et al. (2005) studied the effect of solution treatment on the microstructure and tensile properties of alloy M963. Their results showed that the alloy M963 exhibited optimal combina- 
tion of strength and ductility after solution treatment at 1210 ${ }^{\circ} \mathrm{C} / 4$ h/air cooling (AC). Silva et al. (2013) also reported that the microstructure of Nb-modified MAR-M247 superalloy presented a homogeneous $\gamma$ matrix with fine $\gamma^{\prime}$ precipitates after solution treatment at $1260{ }^{\circ} \mathrm{C} / 8 \mathrm{~h} / \mathrm{AC}$.

Up to now, systematic analysis of the effect of heat treatment on microstructure and mechanical properties of alloy K439 has hitherto been limited. In the current work, the effect of isochronal solution treatment on the microstructure of K439 alloy has been examined and correlated with the stress rupture properties, which determines the optimum solution treatment of this alloy.

\section{Experimental Procedures}

The cast polycrystalline Ni-base superalloy K439 chosen as the master alloy was re-melted in an induction furnace, and then casted into test bars. The as-cast samples were cut from the assolidified bars. Other samples were prepared by solution treatment at 1,080, 1,120,1,150 and $1,190{ }^{\circ} \mathrm{C}$, respectively, for $4 \mathrm{~h}$ and cooled in air. After solution treatment, samples were treated using the same aging treatment conditions, as shown in Table 1. Metallographic specimens for microstructural investigation were prepared following conventional metallographic techniques and etched with a solution of 25 vol. $\%$ HNO3, 50 vol.\% $\mathrm{HF}$ and 25 vol.\% glycerin. Microstructural observations were conducted using an optical microscope (OM), and a ZEISS SUPRA 55 field-emission scanning electron microscope (FESEM) equipped with an energy-dispersive spectrometer (EDS). The size and volume fractions of $\gamma^{\prime}$ precipitates in various conditions were measured from the SEM micrographs using a semi-automatic image analyzer. For each studied condition, $\gamma^{\prime}$ size and volume fraction were based on statistic measurements including three micrographs and at least 500 particles. Differential scanning calorimeter (DSC) experiments were carried out in order to determine the $\gamma^{\prime}$ solvus, incipient melting, liquidus and solidus temperatures of the as-cast K439 alloy. The stress rupture bars with $5 \mathrm{~mm}$ in diameter and $25 \mathrm{~mm}$ in gauge length were tested under the condition of $760{ }^{\circ} \mathrm{C}$ and $130 \mathrm{MPa}$.

\section{Results and Discussion}

\section{As-Cast Microstructure}

The as-cast microstructure of the K439 alloy, as shown in Fig. 1(a), contains $\gamma$-Ni (Cr, Co) solid solution, petal-like $\gamma / \gamma^{\prime}$ eutectic and blocky MC carbide. The EDS analysis, as listed in Table 2, demonstrates that the MC carbide is enriched in $\mathrm{Nb}$, $\mathrm{Ta}$ and $\mathrm{Ti}$ ( $\mathrm{M}$ represents mainly $\mathrm{Ti}, \mathrm{Nb}$ and $\mathrm{Ta}$ ). Additionally, a plate shape phase exists in the interdendritic regions, as shown

Table 1. Heat treatment schedules of K439 alloy.

\begin{tabular}{ll}
\hline Solution Treatment & Aging Treatment \\
\hline $1080^{\circ} \mathrm{C} / 4 \mathrm{~h} / \mathrm{AC}$ & $1000^{\circ} \mathrm{C} / 6 \mathrm{~h} / \mathrm{AC}+800^{\circ} \mathrm{C} / 16 \mathrm{~h} / \mathrm{AC}$ \\
$1120^{\circ} \mathrm{C} / 4 \mathrm{~h} / \mathrm{AC}$ & $1000^{\circ} \mathrm{C} / 6 \mathrm{~h} / \mathrm{AC}+800^{\circ} \mathrm{C} / 16 \mathrm{~h} / \mathrm{AC}$ \\
$1150^{\circ} \mathrm{C} / 4 \mathrm{~h} / \mathrm{AC}$ & $1000^{\circ} \mathrm{C} / 6 \mathrm{~h} / \mathrm{AC}+800^{\circ} \mathrm{C} / 16 \mathrm{~h} / \mathrm{AC}$ \\
$1190^{\circ} \mathrm{C} / 4 \mathrm{~h} / \mathrm{AC}$ & $1000^{\circ} \mathrm{C} / 6 \mathrm{~h} / \mathrm{AC}+800^{\circ} \mathrm{C} / 16 \mathrm{~h} / \mathrm{AC}$ \\
\hline
\end{tabular}
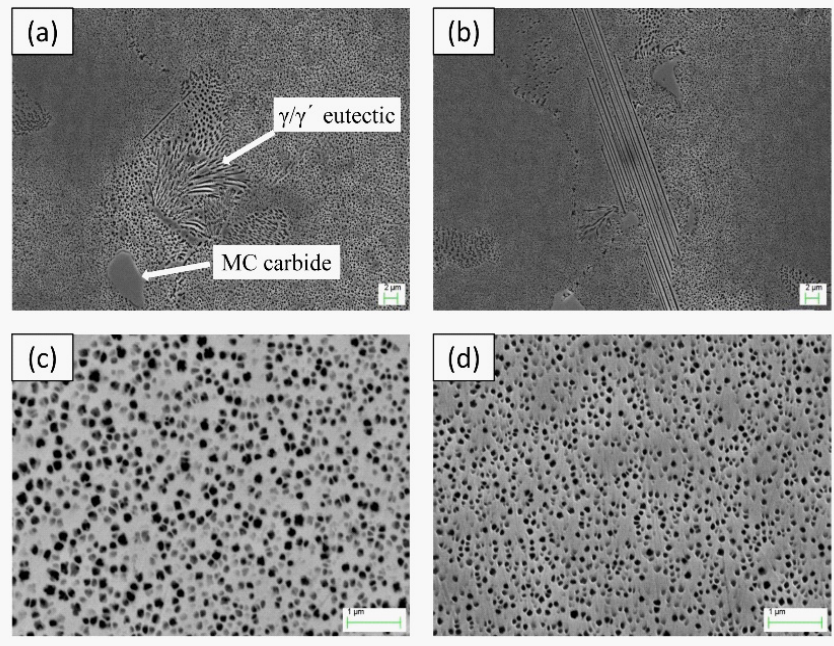

Fig. 1. SEM micrographs showing typical cast microstructures: (a) $\gamma / \gamma^{\prime}$ eutectic and MC carbide; (b) $\eta$ phase; (c) $\gamma^{\prime}$ precipitates at interdendritic region; and (d) $\gamma^{\prime}$ precipitates at dendritic core.

Table 2. EDS analysis result of MC carbide and $\eta$ phase in the as-cast K439 (wt.\%).

\begin{tabular}{ccccccccc}
\hline Phase & $\mathbf{C}$ & $\mathbf{A l}$ & $\mathbf{T i}$ & $\mathbf{C r}$ & $\mathbf{N i}$ & $\mathbf{N b}$ & $\mathbf{T a}$ & $\mathbf{C o}$ \\
\hline $\boldsymbol{\eta}$ & - & 3.54 & 12.51 & 6.01 & 61.06 & 3.81 & 2.23 & 10.84 \\
\hline $\mathbf{M C}$ & 4.09 & 0.15 & 31.68 & 1.32 & 2.57 & 33.83 & 26.36 & - \\
\hline
\end{tabular}

in Fig. 1(b). The EDS analysis in Table 2 shows that this plate shape phase is enriched in Ti. It could be determined to be $\eta$ phase, with the same morphology observed in GTD-111 alloy (Sajjadi et al., 2006) and Ni-Co-based superalloy (Cui et al., 2008). The $\gamma^{\prime}$-Ni3Al particles at interdendritic (Fig. 1c) are coarse and disordered, while the $\gamma^{\prime}$ particles at dendrite (Fig. 1d) are fine and regular.

\section{DSC Analysis}

The DSC testing results of the as-cast alloy is shown in Fig. 2. It indicates that the solidus and liquidus of K439 alloy are 1273.5 and $1356.8^{\circ} \mathrm{C}$, respectively, and the majority of $\gamma^{\prime}$ phase dissolve into solid solution in the temperatures range of 1,080 $1,150{ }^{\circ} \mathrm{C}$. There is another endothermic peak at the temperature approximately $1,200^{\circ} \mathrm{C}$, induced by incipient melting.

\section{Solution Heat Treatment Microstructure}

Based on the results of the DSC analysis, the temperature of solution treatment is chosen as 1,080,1,120,1,150 and 1,190 ${ }^{\circ} \mathrm{C}$, respectively, for $4 \mathrm{~h}$ followed by air cooling, and then subjected to the same aging treatment. Typical microstructures of the alloy after different heat treatment are shown in Fig. 3 and Fig. 4.

Examination of the microstructures of K439 alloy with the solution treatment of $1,080{ }^{\circ} \mathrm{C} / 4 \mathrm{~h}$, as shown in Fig. 3(a) and 3 (b), reveals that all of the $\gamma^{\prime}$ precipitates in dendritic region have dissolved entirely, while the $\gamma^{\prime}$ precipitates in the interdendritic region, as well as $\eta$ phase, are solutioned partly. When 


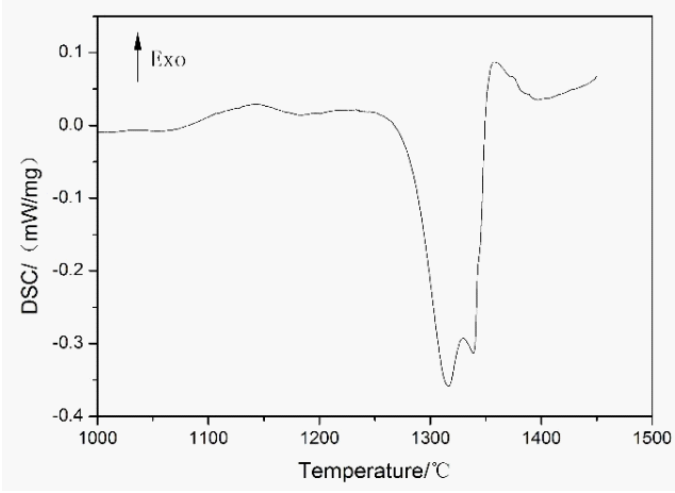

Fig. 2. DSC testing curve of K439 alloy.
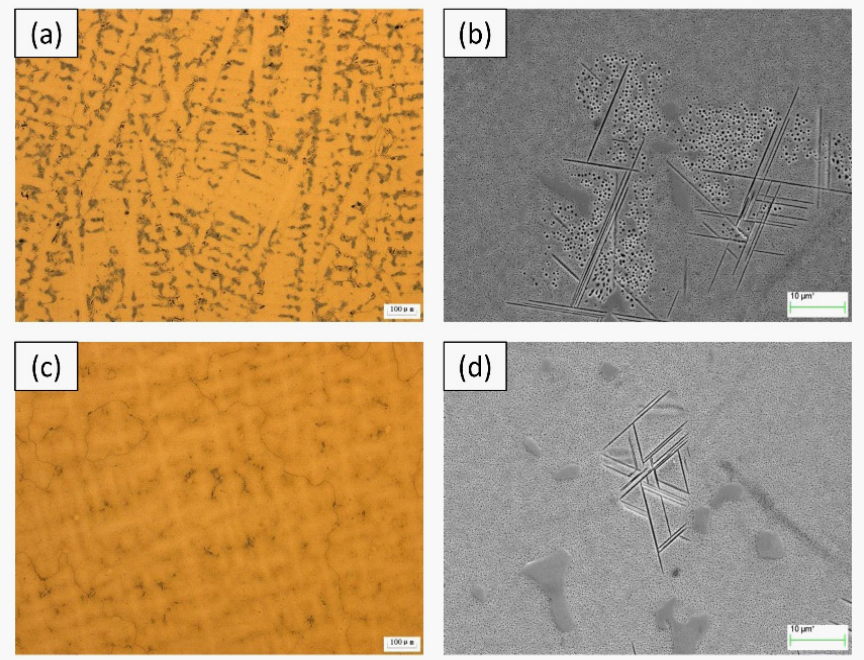

Fig. 3. Microstructures of solution treated at $1080^{\circ} \mathrm{C}$ and $1120^{\circ} \mathrm{C}$ : (a) and (c): optical microstructure of dendritic structure after solution treated at $1080^{\circ} \mathrm{C}$ and $1120^{\circ} \mathrm{C}$; (b) and (d): scanning electron micrographs after solution treated at $1080^{\circ} \mathrm{C}$ and $1120^{\circ} \mathrm{C}$.
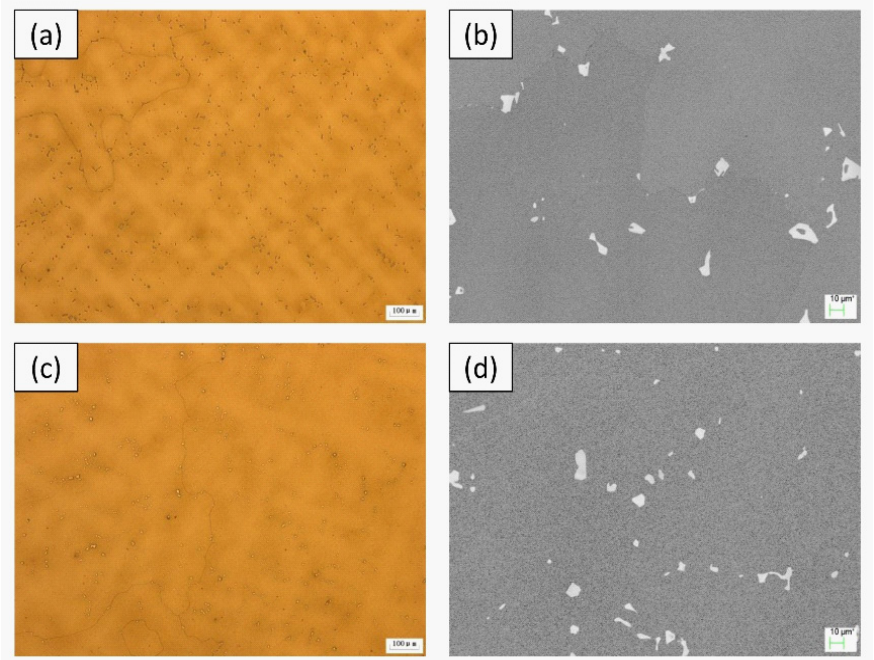

Fig. 4. Microstructures of solution treated at $1150^{\circ} \mathrm{C}$ and $1190^{\circ} \mathrm{C}$ : (a) and (c): optical microstructure of dendritic structure after solution treated at $1150^{\circ} \mathrm{C}$ and $1190^{\circ} \mathrm{C}$; (b) and (d): scanning electron micrographs after solution treated at $1150^{\circ} \mathrm{C}$ and $1190^{\circ} \mathrm{C}$. the solution temperature increases from 1,080 to $1,120^{\circ} \mathrm{C}$, the $\gamma^{\prime}$ phase dissolves completely, but $\eta$ phase is still observed in the interdendritic region, as shown in Fig. 3(c) and 3(d). Based on this observation, the solution temperature of $\gamma^{\prime}$ phase is approximately $1,120^{\circ} \mathrm{C}$.

In the case of solution treatment of $1,150{ }^{\circ} \mathrm{C}$ and $1,190{ }^{\circ} \mathrm{C}$, the dendritic structure almost disappears and the area of interdendritic region decreases, which can be readily understood by comparing Fig 3 and Fig 4 . After the solution treatment at 1,150 ${ }^{\circ} \mathrm{C}$, a uniform microstructure is observed, and the fine $\gamma$ ' precipitates with a mean size about $0.21 \mu \mathrm{m}$ distribute homogenously. Furthermore, all of the $\gamma^{\prime}$ and $\eta$ are dissolved and a uniform microstructure is observed, as shown in Fig. 4(b) and 4(d).

Fig. 5 is a SEM image of K439 alloy after solution treatment at $1,210{ }^{\circ} \mathrm{C}$ for $4 \mathrm{~h}$. It can be seen that the melting point of $\mathrm{K} 439$ alloy is $1,210{ }^{\circ} \mathrm{C}$, which is significantly lower than $\mathrm{K} 4169\left(1,343{ }^{\circ} \mathrm{C}\right)$ and Mar-M247 alloy $\left(1,340{ }^{\circ} \mathrm{C}\right)$. Based on the above results, the fully solution treatment of K439 alloy may be estimated to be $1,150{ }^{\circ} \mathrm{C}$. The solution treatment window, defined as the difference between the incipient melting and $\gamma^{\prime}$ solvus temperatures, is about $60{ }^{\circ} \mathrm{C}$ (from 1,150 to 1,210 $\left.{ }^{\circ} \mathrm{C}\right)$.

The SEM micrographs of $\gamma^{\prime}$ phase in the dendritic region with different solution temperatures are indicated in Fig. 6 . The morphology of $\gamma^{\prime}$ precipitates remain spheroidal for all testing conditions, mainly due to the smaller size. Bradley et al. (1988) and Calliari et al. (1999) reported a transition of $\gamma^{\prime}$ precipitates from spherical to cubic shape in U720, which occurred when the average diameter of the particles exceeded $500 \mathrm{~nm}$, a value higher than those reported for other types of superalloys (about $300 \mathrm{~nm}$ ).

The evolution of average size and volume fraction of $\gamma^{\prime}$ phase with different solution temperatures followed by the same aging treatment is depicted in Fig. 7. As the solution temperature increases from 1,080 to $1,120{ }^{\circ} \mathrm{C}$, the average precipitate size and volume fraction increase from 167 to $200 \mathrm{~nm}$ and from 15.3 to $22.0 \%$, respectively, due to the complete dissolution of $\gamma^{\prime}$ phase. As the relative effect is less pronounced from 1,120 to $1,150{ }^{\circ} \mathrm{C}$, the $\gamma^{\prime}$ size and volume fraction increase slightly from 22.0 to $23.0 \%$ and from 200 to $210 \mathrm{~nm}$, respectively. This may be related to the further solution of $\eta$ phase which provides

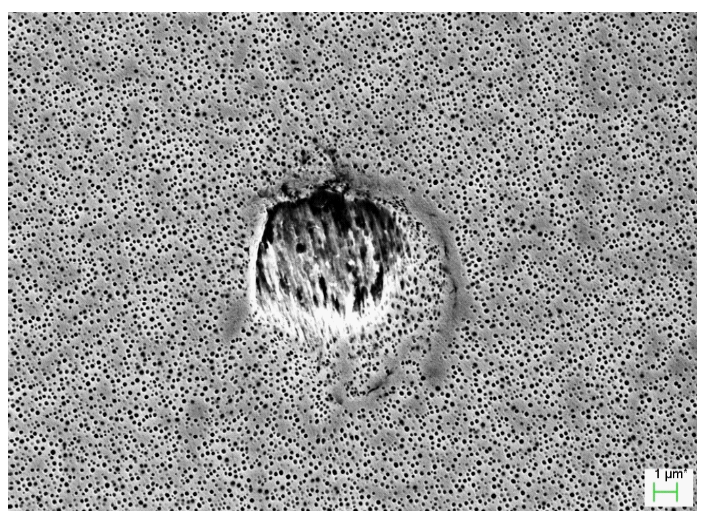

Fig. 5. Microstructure of incipient melting after solution treatment at $1210^{\circ} \mathrm{C} / 4 \mathrm{~h}$. 

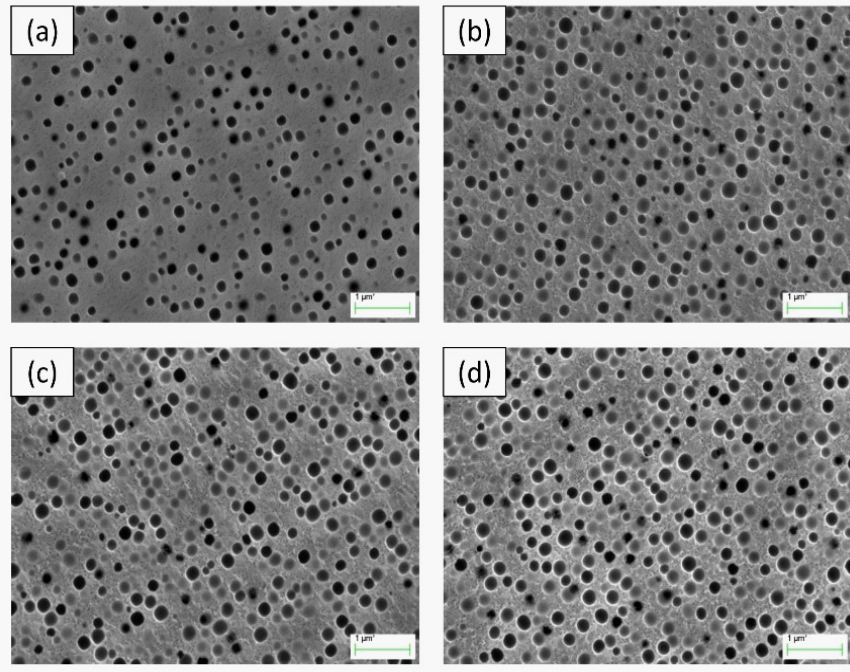

Fig. 6. SEM micrographs of $\gamma^{\prime}$ phase in the dendritic with different solution temperatures: (a) $1080^{\circ} \mathrm{C}$; (b) $1120^{\circ} \mathrm{C}$; (c) $1150^{\circ} \mathrm{C}$; and (d) $1190^{\circ} \mathrm{C}$.

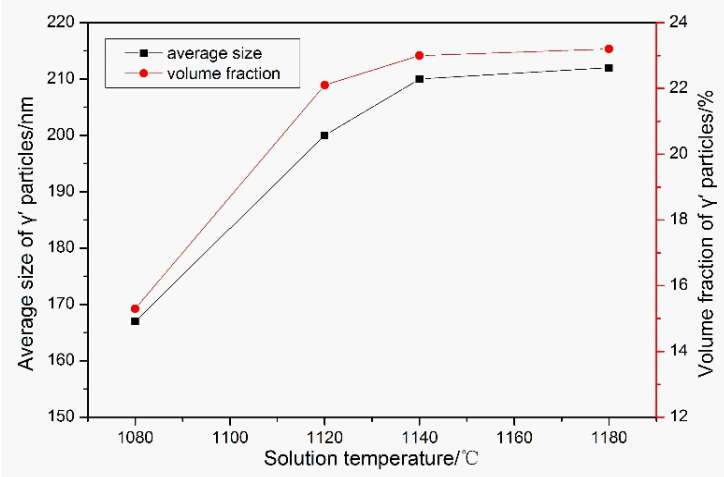

Fig. 7. Evolution of average size and volume fraction of $\gamma^{\prime}$ phase in the dendritic with different solution temperatures.

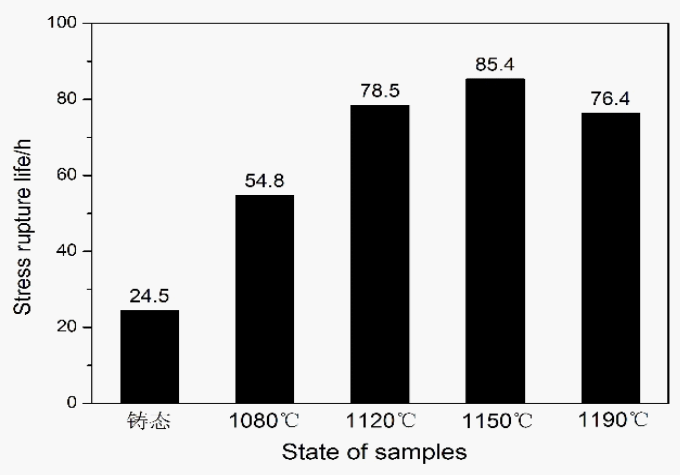

Fig. 8. Stress rupture lives of K439 alloy at different solution temperatures after the same aging under the testing condition of $760^{\circ} \mathrm{C} / 130 \mathrm{MPa}$. $\gamma^{\prime}$-forming elements for subsequent aging. However, very little changes in the size and volume fraction are observed when the temperature is increased from 1,150 to $1,190^{\circ} \mathrm{C}$, indicating that a near equilibrium and steady state condition is reached.

\section{Stress Rupture Properties}

The stress rupture lifetime of alloy K439 with different solution temperatures while with the same aging is tested under the testing condition of $760^{\circ} \mathrm{C} / 130 \mathrm{MPa}$, as shown in Fig. 8, based on the average values of three measurements for each condition. The results in Fig. 8 demonstrate that the as-cast alloy has the shortest lifetime of $24.5 \mathrm{~h}$. The stress rupture lifetime increases remarkably with the solution temperature, which reaches to the maximum value at the solution temperature of 1,150 ${ }^{\circ} \mathrm{C}$ for $85.4 \mathrm{~h}$. However, the stress rupture lifetime shortens to $76.4 \mathrm{~h}$ after solution treatment at $1,190{ }^{\circ} \mathrm{C}$, which is a slightly lower than that after solution treatment at $1,150{ }^{\circ} \mathrm{C}$.

The as-cast microstructures of alloy K439 contain a large fraction of coarsen $\gamma^{\prime}, \gamma / \gamma^{\prime}$ eutectic and $\eta$ phase in the interdendritic regions, while solution treatment can refine the microstructure, and hence the creep resistance can be improved and the stress rupture lifetime can be prolonged, which is consistent with the previous studies on other superalloys (Li et al., 2011). With the solution temperature increases from 1,080 to 1,150 ${ }^{\circ} \mathrm{C}$, the coarsen $\gamma^{\prime}, \gamma / \gamma^{\prime}$ eutectic and $\eta$ phase dissolve gradually, resulting in a uniform microstructure at $1,140{ }^{\circ} \mathrm{C}$. On the other hand, the size and volume fraction of $\gamma^{\prime}$ particles increase, so that the $\gamma-\gamma^{\prime}$ interfacial area increases while the inter-particle spacing decreases, leading to increment of resistance to dislocations (Jackson et al., 1977; Park et al., 1995). Therefore, the stress rupture lifetime of $\mathrm{K} 439$ alloy at $760{ }^{\circ} \mathrm{C} / 530 \mathrm{MPa}$ increases with the solution temperature. The stress rupture lifetime after solution treatment at $1,190{ }^{\circ} \mathrm{C}$ was a slightly lower than that after solution treatment at $1,150^{\circ} \mathrm{C}$, which may be attributed to the small difference in the size of the fine $\gamma^{\prime}$ particles.

\section{Conclusions}

(1) The microstructure of K439 alloy is improved by the hightemperature solution treatments. After solution treatment at $1,150{ }^{\circ} \mathrm{C}$, a uniform microstructure is observed, and the fine $\gamma^{\prime}$ precipitates with a mean size about $0.21 \mu \mathrm{m}$ distribute homogenously.

(2) The stress rupture lifetime of $\mathrm{K} 439$ alloy at $760^{\circ} \mathrm{C} / 530 \mathrm{MPa}$ increased with the solution temperature and reached to the maximum value with the solution temperature of $1,150{ }^{\circ} \mathrm{C}$.

(3) Based on the compromise of the microstructures and stress rupture properties of $\mathrm{K} 439$ alloy, the optimum solution treatment is determined to be $1,150{ }^{\circ} \mathrm{C} / 4 \mathrm{~h}$ followed by air cooling.

\section{Acknowledgments}

The authors are grateful to the financial support provided by National Key R\&D Program of China (No. 2016YFB0701402) and Aeronautical Science Foundation of China (No. 2015ZE21006). 


\section{References}

Bradley EF (1988) Superalloys: A. Technical Guide, ASM International.

Calliari I, Magrini M, and Dabala M (1999) Microstructural evolution of udimet 720 superalloy. J. Mater. Eng. Perf. 8: 111-115.

Cui CY, YF Gu, and DH Ping (2008) Phase constituents and compressive yield Stress of Ni-Co base Alloys. Mater Trans. 3: 424-427.

Cone FP. Observation on the Development of Delta Phase in In718 Alloy[A]. In: Loria E A, ed. Superalloys 718, 625, 706 and Various Derivates. Pennsylvnia, USA: TMS. 2001: 323-332.

Demers V, S Turenne, and O Scalzo (2015) Impact of binders on viscosity of low-pressure powder injection molded Inconel 718 superalloy. J. Mater. Sci. 7: 2893-2902.

Dong JX, XS Xie, and SH Zhang (1993) Enhancements of thermal structure stability in a Ni-base superalloy. Scripta. Metall. Et. Mater. 12: 1477-1482.

Dong JX, XS Xie, and SH Zhang (1995) Coarsening behavior of $\gamma^{\prime \prime}$ precipitates in modified inconel 718 superalloy. Scripta. Metall. Et. Mater. 12: 1933-1940.

He LZ, Q Zheng, and XF Sun (2005) Effect of heat treatment on microstructures and tensile properties of Ni-base superalloy M963. Mater. Sci. Eng. A. 1-2: 128-136.

Jackson JJ, MJ Donachie, and M Gell (1977) The effect of volume percent of fine $\gamma^{\prime}$ on creep in Ds Mar-M200+Hf. Metall. Mater.
Trans. A. 10: 1615-1620.

Li P, S Li, and Y Han (2011) Influence of solution heat treatment on microstructure and stress rupture properties of a Ni3 Al base single crystal superalloy IC6SX. Intermetallics. 2: 182-186.

Long F, YS Yoo, and CY Jo (2009) Phase transformation of $\eta$ and $\sigma$ phases in an experimental nickel-based superalloy. J. Alloy. Compd. 1-2: 181-187.

Park LJ, YG Kim, and SH Hong (1995) Effect of solution treatment on the stress rupture property of MA ODS Ni-base superalloy at 760 ${ }^{\circ}$ C. Scripta. Metall. Et. Mater. 7: 1127-1132.

Sajjadi SA, S Nategh, and RIL Guthrie (2002) Study of microstructure and mechanical properties of high performance Ni-base superalloy GTD-111. Mater. Sci. Eng. A. 1-2: 484-489.

Silva PRSAE, R Baldan, and CA Nunes (2013) Solution heat-treatment of Nb-modified MAR-M247 superalloy. Mater. Charact. 75: 214-219.

Sajjadi SA, SM Zebarjad, and RIL Guthrie (2006) Microstructure evolution of high-performance Ni-base superalloy GTD-111 with heat treatment parameters. J. Mater. Process Tech. 1-3: 376-381.

Wang X, Y Zhou, and Z Zhao (2015) Effects of Solutioning on the Dissolution and Coarsening of $\gamma^{\prime}$ Precipitates in a Nickel-Based Superalloy. J. Mater. Eng. Perform. 4: 1492-1504.

Whitmore L, MR Ahmadi, and L Guetaz (2014) The microstructure of heat-treated nickel-based superalloy 718Plus. Mater. Sci. Eng. A. 29: $39-45$. 